\title{
Research Paper: The Prevalence of Low Back Pain and Its Relation With Backpack Weight Among Iranian Students
}

\author{
Fariba Raeisi $^{{ }^{*}}$, Amir Massoud Arab ${ }^{1}$, Moslehedin Adib Hesami ${ }^{1}$ (C)
}

1. Department of Physiotherapy, University of Social Welfare and Rehabilitation Sciences, Tehran, Iran.

Citation Raeisi F, Arab AM, Adib Hesami M. The Prevalence of Low Back Pain and Its Relation With Backpack Weight Among Iranian Students. Physical Treatments. 2018; 7(4):193-196. http://dx.doi.org/10.32598/ptj.7.4.193

Funding: See Page 196

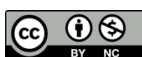

Article info:

Received: 10 Jul 2017

Accepted: 25 Oct 2017

Available Online: 01 Jan 2018
Keywords:

Low Back Pain, Students, Backpacks, Adolescents

\begin{abstract}
A B S T RA C T
Purpose: Several studies have reported that musculoskeletal disorders and discomforts experienced by children and adolescent students are closely related to the weight of bags or backpacks carried by them. Since students are at growth and spinal development age, attention to the pressures on their bodies is important. These pressures can cause musculoskeletal problems and various growth disorders. This study aimed to investigate the prevalence of Low Back Pain (LBP) and its relation with the backpack weight among students.
\end{abstract}

Methods: This cross-sectional study with non-experimental design was conducted on 2000 elementary and secondary school students (1000 boys and 1000 girls) who were randomly selected from schools in 5 regions of Tehran City, Iran. Students with LBP for more than 6 weeks during the study or during the last 3 years at 3 intervals that each lasted for 1 week or more were listed in a group with LBP and others in a group with no LBP (the control group). The weight of their bags or backpacks was measured over a week, and the average was recorded as the weight of carrying load. The intensity of pain was measured using the Visual Analogue Scale. To examine the prevalence of LBP in students, absolute and relative frequency distribution tests, and for examining the correlation between LBP and weight of backpacks, Independent $t$ test were employed. Furthermore, the Pearson correlation coefficient was used to determine the relationship between the weight of backpacks and the intensity of pain. In addition, logistic regression analysis was used to assess the predictability of LBP based on the backpack weight.

Results: Based on the results, $26 \%$ of students had LBP (29.6\% girls, and $21.8 \%$ boys). Mean \pm SD scores of LBP in girl and boy students were reported as $3.4 \pm 2.8$ and $2.3 \pm 5.8$, respectively. According to t test results, there was a significant difference between the two groups in terms of backpack weight both in girls and boys $(\mathrm{P}<0.05)$. The Pearson correlation test results showed a significant correlation between the weight of backpacks and intensity of LBP among boys $(r=0.26, P=0.007)$ and girls $(r=0.31, P<0.001)$. Furthermore, results of logistic regression analysis indicated that the variable of backpack weight can predict $\mathrm{LBP}(\mathrm{B}=0.52, \mathrm{P}=0.01)$.

Conclusion: The weight of the bags or backpacks carried by children and adolescent students has a significant relationship with the prevalence and intensity of LBP in this age group.

\footnotetext{
* Corresponding Author:

Fariba Raeisi, MSc.

Address: Department of Physiotherapy, University of Social Welfare and Rehabilitation Sciences, Tehran, Iran.

Phone: +98 (21) 22180039

E-mail:f.rkaenat@gmail.com
} 


\section{Highlights}

- There is a significant difference between the two groups in terms of backpack weight both in girls and boys.

- The results of logistic regression analysis indicated that the variable of backpack weight can predict LBP.

\section{Plain Language Summary}

Musculoskeletal disorders and discomforts experienced by children and adolescent students may be related to the weight of bags or backpacks carried by them. Students are at the age of growth and spinal development and attention to the pressures on their bodies is important. This study aimed to investigate the prevalence of Low Back Pain (LBP) and its relation with the backpack weight among students. This cross-sectional study with non-experimental design was conducted on 2000 elementary and secondary school students who were randomly selected from schools in Tehran City, Iran. Students with grouped in LBP group and control group based on the study inclusion criteria. The weight of their bags or backpacks was measured and recorded, too. The intensity of pain was measured using the Visual Analogue Scale. Furthermore, the Pearson correlation coefficient was used to determine the relationship between the weight of backpacks and the intensity of pain. In addition, logistic regression analysis was used to assess the predictability of LBP based on the backpack weight. The Pearson correlation test results showed a significant correlation between the weight of backpacks and intensity of LBP among boys $(r=0.26, P=0.007)$ and girls $(r=0.31$, $\mathrm{P}<0.001)$. Furthermore, results of logistic regression analysis indicated that the variable of backpack weight can predict $\operatorname{LBP}(\mathrm{B}=0.52, \mathrm{P}=0.01)$. Thus, the weight of the bags or backpacks carried by children and adolescent students has a significant relationship with the prevalence and intensity of LBP in this age group.

\section{Introduction}

chools are among the places where students spend most of their time. Since students are at growth and spinal development age, attention to pressure on their bodies is important. Pressure can cause musculoskeletal problems and various growth disorders. The weight of the schoolbags or backpacks carried by the students are among the most important issues, in this regard. Risk factors for musculoskeletal discomfort associated with schoolbag carriage include the combined effects of heavy loads, load shape and size, time spent carrying the load, and position of the load on the body [1].

Carrying of the backpacks, because of the weight distributed between the 2 shoulders, allows students to carry books and school supplies more easily; however, the excessive increase in backpack weight can cause pressure and damage to the shoulder and spine [2]. Studies have shown that musculoskeletal discomforts experienced by growing children are significantly related to backpack loads, and heavy backpack loads can actually result in postural changes. However, the number of these studies are limited [3]. In addition, studies have reported that the amount of musculoskeletal pain associated with bags or backpacks is higher in girls than boys $[4,5]$, while other studies have shown no differences in this regard [6].

The kinematic effects of carrying backpacks include forward lean of head and trunk, muscle imbalances, and changes in posture and walking rhythm [2]. Moreover, carrying heavy backpacks can cause spinal cirrhosis, a non-symmetrical condition of the trunk, and degeneration of the intervertebral discs over time [7]. one-strap backpacks cause more lateral spinal bending and shoulder elevation compared to two-strap ones [2]. Carrying backpacks with weights of more than $15 \%$ of the body weight causes a limitation or failure to maintain a correct posture, and even can reduce lung capacity $[8,9]$.

Low Back Pain (LBP) is one of the most prevalent pains. Approximately $60 \%$ to $80 \%$ of people have experienced LBP during life $[10,11]$. The prevalence of LBP is higher in adults and many studies have evaluated its prevalence among adults. However, the number of studies conducted to assess the prevalence of LBP and spinal problems in children is limited [12]. The prevalence of BBP increases dramatically during adolescence from less than $10 \%$ in the pre-teenage years up to $50 \%$ in 15 - to 16 -year-old teenagers. There is high concern that heavy backpacks carried by adolescents contribute to the development of LBP [4]. This study aimed to investigate the prevalence of LBP and 
its relation with the backpack weight among children and adolescent students in Tehran City, Iran.

\section{Materials and Methods}

This cross-sectional study with non-experimental design was conducted on elementary and secondary school students (boys and girls) who were randomly selected from schools in 5 districts of Tehran (regions 3, 5, 10, 12, and 14). According to similar studies, the sample size was considered 2000 students (1000 boys and 1000 girls). Exclusion criteria were having a history of traumatic injury or fractures in the spinal and pelvic regions, history of hospitalization, rheumatic diseases and having postural disorders like scoliosis. To collect data, a questionnaire was designed surveying demographic characteristics of students, including age, sex, weight of carrying bags or backpacks, satisfaction with the weight of bags or backpacks, and pain in the various spinal regions. Students with LBP for more than 6 weeks during the study or during the last 3 years at 3 intervals that each lasted for 1 week or more were listed in a group with LBP and others in a group without LBP (the control group).

To examine the prevalence of LBP in students, absolute and relative frequency distribution tests, and for examining the correlation between LBP and weight of backpacks, Independent $t$ test were employed. Furthermore, the Pearson correlation coefficient was used to determine the relationship between the weight of backpacks and pain intensity. In addition, logistic regression analysis was used to assess the predictability of LBP based on the backpack weight.

\section{Results}

Of 2000 students participated in the study, 26\% had LBP ( $29.6 \%$ girls, and $21.8 \%$ boys). Mean \pm SD of LBP in girl and boy students were reported as $3.4 \pm 2.8$ and $2.3 \pm 5.8$, respectively according to the Visual Analogue Scale (VAS). Table 1 presents Mean \pm SD scores of backpack weight in both groups and the results of t test. The weight of carrying backpacks was between $300 \mathrm{~g}$ to $12 \mathrm{~kg}$ (Mean \pm SD backpack weight: $4.5 \pm 1.9 \mathrm{~kg})$. There was no interaction between gender and back pain in relation to the backpack weight $(\mathrm{P}=0.09)$. Ac- cording to $t$ test results, there is a significant difference between the two groups in terms of backpack weight both in girls and boys $(\mathrm{P}<0.05)$.

The Pearson correlation test results revealed a significant relationship between the weight of backpacks and intensity of LBP among boys $(\mathrm{r}=0.26, \mathrm{P}=0.007)$ and girls $(\mathrm{r}=0.31$, $\mathrm{P}<0.001)$. Furthermore, the results of logistic regression analysis indicated that backpack weight can predict LBP $(\mathrm{B}=0.52, \mathrm{P}=0.01$ ). Overall, the weight of the bags or backpacks carried by children and adolescent students has a significant relationship with the prevalence and intensity of LBP in this age group.

\section{Discussion}

The results revealed that about $26 \%$ of students had LBP, which is relatively high considering their age. Moreover, based on the results, the prevalence of LBP in students had a significant relationship with the weight of the carrying bags or backpacks, which is consistent with the results of previous studies in this area $[3,13,14]$. The average weight of students' backpacks in the current study was about $4.5 \mathrm{~kg}$, which is lower than the amount reported in previous studies [15-18].

The heavy load of schoolbags found out in this study (300 $\mathrm{g}$ to $12 \mathrm{~kg}$ ) can indicate that some students carry books more than what they need on a daily basis. It is also possible that students had to carry more books because of different school programs or because some books contain higher number of lessons (pages). This makes the bags heavier and exerts excessive pressure on the student's spine. Given the backpack load, it was found that most students with LBP were among those whose weight of bags was above this range.

According to the student's parents, some students carry objects more than needed in their bags or backpacks that makes their schoolbag load heavier than normal range. For normal and painless activity, a normal and controlled pressure must be exerted on the muscles and joints of the body to stimulate them and improve the nutrition of the joints and tissues around them. While, inactivity and decreased normal pressure through disrupting the joint feeding system and reduction of muscle stimulation can cause disorders and muscu-

Table 1. Statistics related to the weight of backpacks carried by students

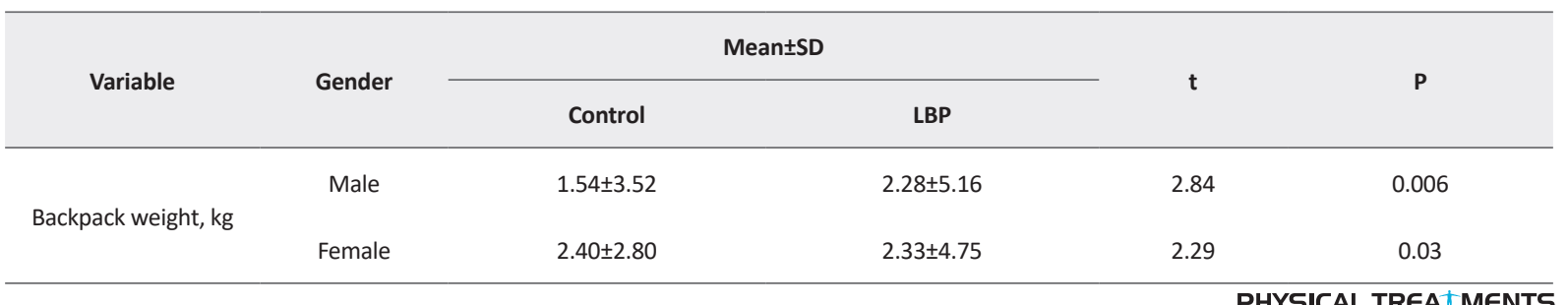

PHYSICAL TREA MENTS 
loskeletal pain, excessive and prolonged pressures can also lead to microtrauma, trauma, and musculoskeletal pain.

For this purpose, it is possible to prevent the occurrence of LBP in students by installing closets for each student and class scheduling by considering the weight of the carried books. This will significantly reduce the cost of treatment for back pain.

\section{Ethical Considerations}

\section{Compliance with ethical guidelines}

All ethical principles were considered in this article. The participants' parents were informed about the purpose of the research and its implementation stages; They were also assured about the confidentiality of their children information; Moreover, They were allowed to leave the study whenever they wish, and if desired, the results of the research would be available to them.

\section{Funding}

This research did not receive any specific grant from funding agencies in the public, commercial, or not-forprofit sectors.

\section{Conflict of interest}

The authors certify that they have no affiliation with or involvement in any organization or entity with any financial interest, or non-financial interest in the subject matter or materials dismissed in this manuscript.

\section{References}

[1] Dochrell S, Kane C, O'keefe E. Schoolbag weight and the effects of schoolbag carriage on secondary school students. Ergonomics. 2006; 9:216-22.

[2] Pascoe DD, Pascoe DE, Wang YT, Shim DM, Kim CK Influence of carrying book bags on gait cycle and posture of youths. Ergonomics. 1997; 40(6):631-40. [DOI:10.1080/001401397187928] [PMID]

[3] Shamsoddini A, Hollisaz M, Hafezi R. Backpack weight and musculoskeletal symptoms in secondary school students, Tehran, Iran. Iranian Journal of Public Health. 2010; 39(4):1205. [PMID] [PMCID]

[4] Sheir-Neiss GI, Kruse RW, Rahman T, Jacobson LP, Pelli JA. The association of backpack use and back pain in adolescents. Spine. 2003; 28(9):922-30. [DOI:10.1097/01. BRS.0000058725.18067.F7] [PMID]
[5] Puckree T, Silal S, Lin J. School bag carriage and pain in schoo children. Disability \& Rehabilitation. 2004; 26(1):54-9. [DOI:10.10 80/09638280310001616376] [PMID]

[6] Negrini S, Carabalona R. Backpacks on! Schoolchildren's perceptions of load, associations with back pain and factors determining the load. Spine. 2002; 27(2):187-95. [DOI:10.1097/00007632-200201150-00014] [PMID]

[7] Kanlayanaphotporn R, Lam L, Williams M, Trott P, Fulton I. Adolescent versus adult responses to vertical spinal loading. Ergonomics. 2001; 44(15):1384-91. [DOI:10.1080/00148130110109694] [PMID]

[8] Lai JP, Jones AY. The effect of shoulder-girdle loading by a school bag on lung volumes in Chinese primary school children. Early Human Development. 2001; 62(1):79-86. [DOI:10.1016/S0378-3782(01)00121-9]

[9] Chansirinukor W, Dansie B, Wilson D, Grimmer K. Effects of backpacks on students: Measurement of cervical and shoulder posture. Australian Journal of physiotherapy. 2001; 47(2):110-6. [DOI:10.1016/S0004-9514(14)60302-0]

[10] Calvo Muoz I, Gómez Conesa A, Sánchez Meca J. Prevalence of low back pain in children and adolescents: A meta-analysis. BMC Pediatrics. 2013; 13:14. [DOI:10.1186/1471-2431-13-14] [PMID] [PMCID]

[11] Kordi R, Rostami M. Low back pain in children and adolescents: An algorithmic clinical approach. Iranian Journal of Pediatrics. 2011; 21(3):259-70. [PMID] [PMCID]

[12] Skaggs DL, Early SD, D'Ambra P, Tolo VT, Kay RM. Back pain and backpacks in school children. Journal of Pediatric Orthopaedics. 2006; 26(3):358-63. [DOI:10.1097/01. bpo.0000217723.14631.6e] [PMID]

[13] Mohseni-Bandpay MA, Bagheri-Nasami M, Fakhri M, AhmadShirvani M, Khaliliyan AR. [Prevalence and risk factors of low back pain in school children age 11-14 years (Persian)]. Journal of Gorgan University of Medical Sciences. 2005; 7(1):79-83.

[14] Negrini S, Carabalona R, Sibilla P. Backpack as a daily load for schoolchildren. The Lancet. 1999; 354(9194):1974. [DOI:10.1016/ S0140-6736(99)04520-1]

[15] Watson KD, Papageorgiou AC, Jones GT, Taylor S, Symmons DP, Silman AJ, et al. Low back pain in schoolchildren: The role of mechanical and psychosocial factors. Archives of Disease in Childhood. 2003; 88(1):12-7. [DOI:10.1136/ adc.88.1.12] [PMID] [PMCID]

[16] Feldman DE, Shrier I, Rossignol M, Abenhaim L. Risk factors for the development of low back pain in adolescence. American Journal of Epidemiology. 2001; 154(1):30-6. [DOI:10.1093/aje/154.1.30] [PMID]

[17] Olsen TL, Anderson RL, Dearwater SR, Kriska AM, Cauley JA, Aaron DJ, et al. The epidemiology of low back pain in an adolescent population. American Journal of Public Health. 1992; 82(4):606-8. [DOI:10.2105/AJPH.82.4.606] [PMID] [PMCID]

[18] Wedderkopp N, Leboeuf Yde C, Andersen LB, Froberg K, Hansen HS. Back pain reporting pattern in a Danish population-based sample of children and adolescents. Spine. 2001; 26(17):1879-83 . [DOI:10.1097/00007632-200109010-00012] [PMID] 